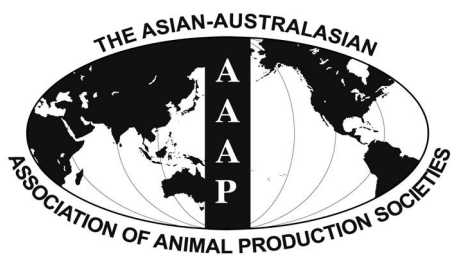

Open Access

Asian Australas. J. Anim. Sci.

Vol. 28, No. 10 : 1380-1387 October 2015

http://dx.doi.org/10.5713/ajas.14.0886

www.ajas.info

pISSN 1011-2367 elSSN 1976-5517

\title{
Correlation between Heart-type Fatty Acid-binding Protein Gene Polymorphism and mRNA Expression with Intramuscular Fat in Baicheng-oil Chicken
}

\author{
Yong Wang ${ }^{\text {a }}$, Jianzhong $\mathrm{He}^{\mathrm{a}}$, Wenxuan Yang ${ }^{1}$, Gemenggul Muhantay, \\ Ying Chen, Jinming Xing, and Jianzhu Liu ${ }^{2}$ * \\ College of Animal Science, Key Laboratory of Tarim Animal Husbandry Science and \\ Technology of Xinjiang Production and Construction Groups, Tarim University, \\ Alar, Xinjiang Uygur Autonomous Region 843300, China
}

\begin{abstract}
This study aims to determine the polymorphism and mRNA expression pattern of the heart-type fatty acid-binding protein $(H-F A B P)$ gene and their association with intramuscular fat (IMF) content in the breast and leg muscles of Baicheng oil chicken (BOC). A total of 720 chickens, including 240 black Baicheng oil chicken (BBOC), 240 silky Baicheng oil chicken (SBOC), and 240 white Baicheng oil chicken (WBOC) were raised. Three genotypes of $H$-FABP gene second extron following $\mathrm{AA}, \mathrm{AB}$, and $\mathrm{BB}$ were detected by polymerase chain reaction-single strand conformation polymorphism (PCR-SSCP) strategy. The G939A site created AA genotype and G956A site created BB genotype. The content of IMF in AA genotype in breast muscle of BBOC was significantly higher than that of $A B(p=0.0176)$ and the genotype in leg muscle of WBOC was significantly higher than that of $A B(p=0.0145)$. The G939A site could be taken as genetic marker for higher IMF content selecting for breast muscle of BBOC and leg muscle of WBOC. The relative mRNA expression of $H-F A B P$ was measured by real-time PCR at 30,60, 90, and $120 \mathrm{~d}$. The IMF content significantly increased with age in both muscles. The mRNA expression level of H-FABP significantly decreased with age in both muscles of the three types of chickens. Moreover, a significant negative correlation between $H$-FABP abundance and IMF content in the leg muscles of WBOC $(\mathrm{p}=0.035)$ was observed. The mRNA expression of $H-F A B P$ negatively correlated with the IMF content in both breast and leg muscles of BOC sat slaughter time. (Key Words: Expression Regularity, Heart-type Fatty Acid-binding Protein (H-FABP), Breast Muscle, Leg Muscle, Baicheng-oil Chicken)
\end{abstract}

\section{INTRODUCTION}

In 2010, Baicheng oil chicken (BOC) was included in the Directory of National Animal Genetic Resources (Amanguli et al., 2014). BOC has gained popularity because of its delicious taste even when cooked

\footnotetext{
* Corresponding Author: Jianzhu Liu. E-mail: liujz@sdau.edu.cn

${ }^{1}$ Inspection Center for the Quality of Agricultural and Sideline Products of Shandong, Zoucheng 273500, China.

${ }^{2}$ College of Veterinary Medicine, Research Center for Animal Disease Control Engineering Shandong, Shandong Agricultural University, Tai an 271018, China.

${ }^{a}$ These two authors contribute equally to this work.

Submitted Nov. 19, 2014; Revised Feb. 3, 2015; Accepted Mar. 12, 2015
}

traditionally using only salt and water (Gemenggul et al., 2013). The BOC can be classified into three main species: black Baicheng oil chicken (BBOC), silky Baicheng oil chicken (SBOC), and white Baicheng oil chicken (WBOC) (Wang et al., 2013). The BOC has great flavor and colored (mainly black) feathers, SBOC exerts therapeutic effects on gynecological diseases and was believed extinct for decades (Gemenggul et al., 2013). The WBOC is covered with white feathers and thrives at higher altitudes than BBOC and SBOC. The BOC has a history of over 300 years and resides in the townships of Baicheng County, Xinjiang Uygur Autonomous Region, China at an altitude of more than 2,300 m (Amanguli et al., 2014). Considering the the slow growth rate and low feed conversion ratio of BOC, 
breeders have introduced other species of chicken since the 1940s. The continuous hybridization resulting from the introduction of other varieties has posed a threat on the survival of these thoroughbred chickens (Gemenggul et al., 2013; Wang et al., 2013).

Intramuscular fat (IMF) content is closely associated with the tenderness, juiciness, and special flavor of meat (Pang et al., 2006). The IMF content depends on the balance between the synthesis and degradation of triacylglycerol, the major component of IMF in muscles and is stored within intramuscular adipocytes (Hocquette et al., 2010).

Fatty acid-binding proteins (FABPs) are cytosolic lowmolecular-weight proteins that can be classified into at least nine types: liver, myelin, adipocyte, brain, heart, intestinal, epidermal, testis, and ileal (Chmurzynska, 2006). The members of the FABP gene family have different distribution patterns and functions (Ma et al., 2010). Hearttype fatty acid-binding protein (H-FABP) regulates IMF deposition, promotes the intracellular transport and cellular absorption of fatty acids, and facilitates the utilization and storage of fats (Zhang et al., 2013). And A-FABP are markers of intramuscular adipocytes in which IMF is mainly stored (Hocquette et al., 2010).

The H-FABP is located on chicken chromosome 23 and is expressed in several tissues; the cellular function of the $H$-FABP gene has yet to be elucidated in detail (Tyra et al., 2011). Previous studies revealed that H-FABP influences meat quality and IMF content in chickens (Li et al., 2008; Tu et al., 2010), pigs (Cho et al., 2009), sheep (Zhang et al., 2013) and in cattle (Brandstetter et al., 2002). The mRNA expression of the $H-F A B P$ gene significantly varies in the different tissues of sheep (Huang et al., 2006; Zhang et al., 2013) and swine ( $\mathrm{Li}$ et al., 2007). However, the mRNA expression pattern of this gene in BOC chickens remains unclear to date ( $\mathrm{Li}$ et al., 2010; Tu et al., 2010). In the present study, we measured $H-F A B P$ mRNA expression and IMF content in the breast and leg muscles of BBOC, SBOC, and WBOC. This study aims to determine the temporal and spatial mRNA expression patterns of $H-F A B P$ and to identify the correlation between $H-F A B P$ gene mRNA and IMF content in the three types of BOCs. The results of this study may provide a theoretical foundation for further research on the functions of the $H-F A B P$ gene in chickens.

\section{MATERIALS AND METHODS}

\section{Animals}

All parent chickens were collected from Heiyingshan in Baicheng County, the provenance of BOCs. A total of 720 healthy BOCs, including 240 BBOCs, 240 SBOCs, and 240 WBOCs, with half males and half females on each group, were raised on the ground in the same chamber, and their fathers were brother and their mothers were sister for each group. The BOCs were raised under the same conditions at the experimental station of animals in Tarim University and were provided ad libitum access to food and water. The protocol was accepted by the Tarim University Institutional Animal Care and Use Committee.

\section{Sample harvest}

In total, 30 male and 30 female chickens from each group were slaughtered through avascularization at 30, 60, 90 , and $120 \mathrm{~d}$ with the same interval, which could display more clear temporal and spatial mRNA expression patterns of $H-F A B P$, and IMF content trends. Breast muscles and leg muscles were collected and then stored at $-20^{\circ} \mathrm{C}$ for IMF content mensuration and at $-80^{\circ} \mathrm{C}$ for RNA extraction.

\section{Intramuscular fat content}

The IMF content (expressed as weight percentage) was measured using the Soxhlet petroleum-ether extraction method in accordance with the Chinese National Standards $\mathrm{GB} / \mathrm{T}$ 5009.6.2004, and the results of IMF content were displayed as weight percentage.

\section{Design and synthesis of the primers}

Primers were designed to amplify the second exon of $\mathrm{H}$ FABP by Primer 5.0 according to the H-FABP sequence of Gallus gallus (GenBank accession No. AY648562): HFABP, 5'- CGACAAGGCGACGGTGAA -3' (forward) and 5'- TGGGGCAGGAAGGAGTTT -3' (reverse). Total genomic DNA was abstracted from blood of wing vein by a MasterPure DNA Purification Kit (Beijing SinoGene Scientific Co. Ltd., Beijing, China) following the attached protocol. PCR reaction was performed in a $20 \mu \mathrm{L}$ system containing $0.5 \mu \mathrm{L}$ Primer $(10 \mu \mathrm{M}), 8 \mu \mathrm{L}$ ddH2O, $1 \mu \mathrm{L}$ gDNA, and $10 \mu \mathrm{L} 2 \times \mathrm{SG}$ PCR MasterMix (Beijing SinoGene Scientific Co. Ltd., China). The PCR amplification protocol was $94^{\circ} \mathrm{C}$ for 3 min, followed by 35 cycles of $94^{\circ} \mathrm{C}$ for $30 \mathrm{~s}, 60^{\circ} \mathrm{C}$ for $30 \mathrm{~s}$ and $72^{\circ} \mathrm{C}$ for $30 \mathrm{~s}$, and a final extension at $72^{\circ} \mathrm{C}$ for $10 \mathrm{~min}$. The PCR products were detected on $1 \%$ agarose gel. Fifty $\mu \mathrm{L}$ expansion system was carried out in order to recover the products.

The expected size PCR products were analyzed by the technique of polymerase chain reaction-single strand conformation polymorphism (PCR-SSCP). The PCR products were diluted with PCR-SSCP buffer including $0.1 \%$ xylene cyanol in formamide and $0.1 \%$ bromophenol blue. The mixtures were degenerated at $98^{\circ} \mathrm{C}$ for $10 \mathrm{~min}$ and cooled in ice for $5 \mathrm{~min}$, and then transferred to a $12 \%$ polyacrylamide gel and a $10 \times \mathrm{TBE}$ buffer. The gels were performed at $4^{\circ} \mathrm{C}$ for $250 \mathrm{~V}, 10$ min and $56 \mathrm{~V}, 16 \mathrm{~h}$. The gels were stained according to a standard protocol (Wang et al., 2007). 


\section{RNA extraction and reverse transcription}

Total RNA was extracted using Trizol reagent (Invitrogen, Carlsbad CA, USA). The quality and quantity of the isolated RNA were assessed by BioPhotometer (Eppendorf, Hamburg, Germany) and 2\% gel electrophoresis, followed by reverse transcription. The 20 $\mu \mathrm{L}$ reverse transcription reaction system comprised the following: $2 \mu \mathrm{g}$ of RNA, $1 \mu \mathrm{L}$ of Oligo (dT) 15 Primer, 1 $\mu \mathrm{L}$ of random primers, $10 \mu \mathrm{L}$ of nuclease-free water, $1 \mu \mathrm{L}$ of GoScript TM Reverse Transcriptase, 1.6 $\mu \mathrm{L}$ of nucleasefree water, $0.4 \mu \mathrm{L}$ of Recombinant RNasin Ribonuclease Inhibitor, $4 \mu \mathrm{L}$ of GoScript TM $5 \times$ reaction buffer, $2 \mu \mathrm{L}$ of $\mathrm{MgCl}_{2}(25 \mathrm{mM})$, and $1 \mu \mathrm{L}$ of PCR Nucleotide Mix. The reaction procedure was performed under the following conditions: denaturation for $5 \mathrm{~min}$ at $70^{\circ} \mathrm{C}$, annealing for 5 min at $25^{\circ} \mathrm{C}$, extending annealing for $60 \mathrm{~min}$ at $42^{\circ} \mathrm{C}$, inactivated reverse transcriptase for $15 \mathrm{~min}$ at $70^{\circ} \mathrm{C}$, and then storage at $4^{\circ} \mathrm{C}$.

\section{Real-time polymerase chain reaction}

The mRNA expression level of $H$-FABP was measured using a 7500 Real-Time PCR System with a $20 \mu \mathrm{L}$ reaction system containing the following: $1 \mu \mathrm{L}$ of cDNA, $10 \mu \mathrm{L}$ of $2 \times$ SYBR Premix DimerEraser, $0.6 \mu \mathrm{L}$ of each genespecific primer $(100 \mathrm{nM}$ ), and $0.4 \mu \mathrm{L}$ of ROX (passive reference dye). The reaction procedure was performed as follows: 1 cycle of $95^{\circ} \mathrm{C}$ for $30 \mathrm{~s} ; 39$ cycles of $95^{\circ} \mathrm{C}$ for $5 \mathrm{~s}$, $60^{\circ} \mathrm{C}$ for $30 \mathrm{~s}$, and $72^{\circ} \mathrm{C}$ for $60 \mathrm{~s}$; and 1 cycle of $95^{\circ} \mathrm{C}$ for $15 \mathrm{~s}, 60^{\circ} \mathrm{C}$ for $60 \mathrm{~s}, 95^{\circ} \mathrm{C}$ for $30 \mathrm{~s}$, and $60^{\circ} \mathrm{C}$ for $15 \mathrm{~s}$. $\beta$ Actin was used as the house-keeping gene. The following primers, which were designed through Oligo 6.0 and Primer 5.0 and synthesized by Invitrogen Corporation, were used: H-FABP, 5'-CAGAAGTGGGATGGGAAGGAGA-3' (forward) and 5'-TCATAGGTGCGGGTGGAGAC-3' (reverse); $\beta$-actin, 5'-AACACCCACACCCCTGTGAT-3' (forward) and 5'-TGAGTCAAGCGCCAAAAGAA-3' (reverse). The relative expression of these genes was calculated by the $2^{-\Delta \Delta \mathrm{Ct}}$ method (Li et al., 2012).

\section{Statistical analysis}

POPGENE software (ver.1.31) was used to analyze the frequencies of alleles and genotypes, and the polymorphic information content (PIC) was analyzed by PowerMaker software (ver.3.25). The association between the polymorphism of $H$-FABP gene and IMF content was performed by SAS statistical software package, version 9.0 (SAS Institute, Inc., Cary, NC, USA) using the SAS software PROC general linear model procedures to determine the significance.

$$
\mathrm{Y}=\mu+\mathrm{G}+\mathrm{S}+\mathrm{f}+\mathrm{h}+\mathrm{e}
$$

Here $\mathrm{Y}=$ the dependent variable, $\mu=$ the population mean, $G=$ fixed effects of breed, $S=$ fixed effects of sex, $f$
$=$ family, $\mathrm{h}=$ random effects, and $\mathrm{e}=$ random error. The interaction $\mathrm{G} \times \mathrm{S}$ was not significant for any trait and therefore was not included in the model. The data of IMF and mRNA $\left(2^{-\Delta \Delta_{\varepsilon-}}\right)$ were analyzed through the method of one-way analysis of variance analysis and the association between IMF and mRNA $\left(2^{-\Delta C t}\right)(\mathrm{Tu}$ et al., 2010) were analyzed using Pearson's correlation coefficient both performed with SPSS 17.0 software (American SPSS Corporation, headquartered in Chicago).

\section{RESULTS}

\section{Intramuscular fat content}

The changes in IMF content with age in the different tissues are shown in Figure 1 and 2. Significant differences in IMF content were observed between 120 and $30 \mathrm{~d}$ in the breast muscles of BBOC $(p=0.031)$ and WBOC $(p=$ $0.027)$ as well as in the leg muscles of BBOC $(p=0.001)$, SBOC $(p=0.029)$, and WBOC $(p=0.019)$. Significant differences were also detected between 120 and $60 \mathrm{~d}$ in the leg muscles of BBOC $(p=0.005)$ and WBOC $(p=0.040)$. Moreover, significant differences were found between 90 and $30 \mathrm{~d}$ in $\operatorname{BBOC}(\mathrm{p}=0.033)$

\section{Genotype and allele frequency}

Three genotypes of $H-F A B P$ gene second extron following AA, AB, and BB were detected by PCR-SSCP strategy. The genotypes of $\mathrm{AA}$ and $\mathrm{BB}$ were sequenced and compared with the sequence AY 648562 acquired from Genbank, respectively. Two mutation sites were detected in

\section{Breast Muscle}

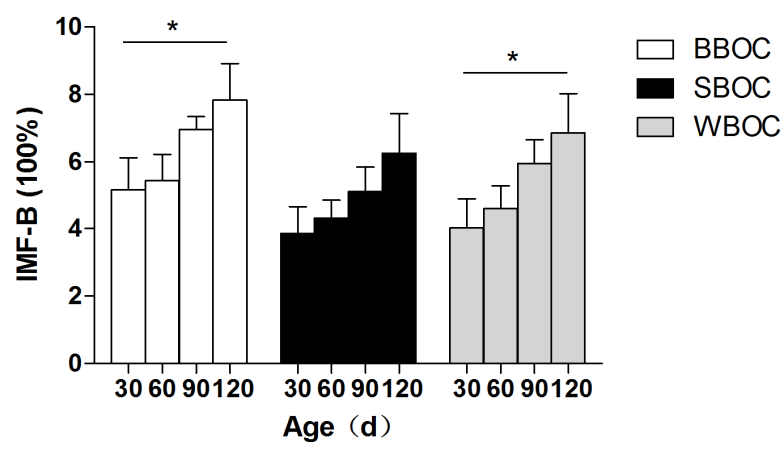

Figure 1. IMF content in breast muscles of BBOC, SBOC, and WBOC at 30 d, 60 d, 90 d, and 120 d. Samples of breast muscles of BBOC, SBOC, and WBOC were harvested at $30 \mathrm{~d}, 60 \mathrm{~d}, 90 \mathrm{~d}$, and $120 \mathrm{~d}$. The IMF content were measured by Soxhlet petroleumether extraction method according to the Chinese National Standards GB/T 5009.6.2004. Data are presented as the mean \pm standard error of the mean for each group ( $\mathrm{n}=60$ per group). * $\mathrm{p}<0.05$. IMF, intramuscular fat; BBOC, black Baicheng oil chicken; SBOC, silky Baicheng oil chicken; WBOC, white Baicheng oil chicken. 


\section{Leg Muscle}

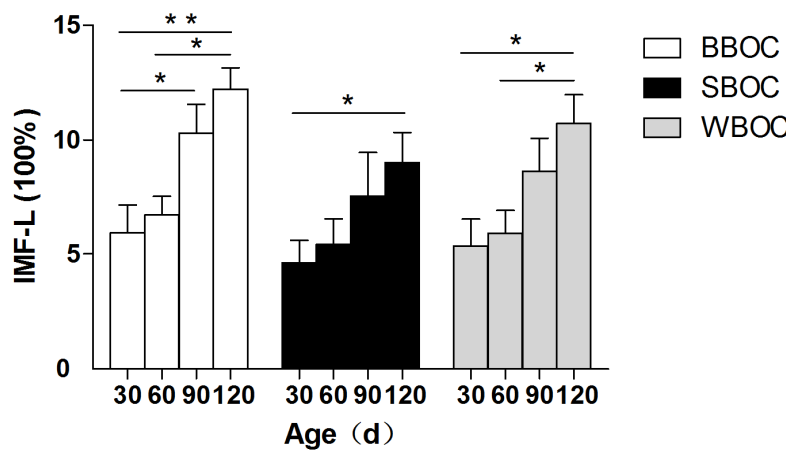

Figure 2. IMF content in leg muscles of BBOC, SBOC, and WBOC at $30 \mathrm{~d}, 60 \mathrm{~d}, 90 \mathrm{~d}$, and $120 \mathrm{~d}$. Samples of leg muscles of BBOC, SBOC, and WBOC were harvested at $30 \mathrm{~d}, 60 \mathrm{~d}, 90 \mathrm{~d}$, and 120 d. IMF content were measured by Soxhlet petroleum-ether extraction method according to the Chinese National Standards $\mathrm{GB} / \mathrm{T}$ 5009.6.2004. Data are presented as the mean \pm standard error of the mean for each group ( $n=60$ per group). ${ }^{*} \mathrm{p}<0.05$. IMF, intramuscular fat; BBOC, black Baicheng oil chicken; SBOC, silky Baicheng oil chicken; WBOC, white Baicheng oil chicken.

BOC, the G939A site created AA genotype and G956A site created $\mathrm{BB}$ genotype. Genotypic frequency and gene frequency were showed in Table 1. BB was dominant genotype and $\mathrm{B}$ was dominant allele in BBOC, meanwhile, $\mathrm{AA}$ was dominant genotype and $\mathrm{A}$ was dominant allele in both SBOC and WBOC in natural selection. Parameters of genetic polymorphism were displayed in Table 2 . The $x^{2}$ value were $2.676(\mathrm{p}=0.102)$ in BBOC, $3.593(\mathrm{p}=0.058)$ in $\mathrm{SBOC}$ and $1.839(\mathrm{p}=0.175)$ respectively. The population of BOCs fitted with Hardy-Weinberg equilibrium.

\section{Correlation between $\mathrm{H}$-FABP gene polymorphism and intramuscular fat content}

The results of correlation between $H$-FABP gene polymorphism and IMF content of breast muscle and leg muscle were showed in Table 3 and 4, respectively. The results of the least square mean showed that the content of IMF in AA genotype in breast muscle of BBOC was significantly higher than that of $\mathrm{AB}(\mathrm{p}=0.0176)$ and the genotype in leg muscle of WBOC was significantly higher than that of $\mathrm{AB}(\mathrm{p}=0.0145)$.
Table 2. Hereditary character of $H-F A B P$ gene of BOCs

\begin{tabular}{lcccccc}
\hline Breed & Ho & $\mathrm{He}$ & $\mathrm{Ne}$ & $\mathrm{PIC}$ & $x^{2}$ & $\mathrm{p}$ \\
\hline BBOC & 0.442 & 0.350 & 1.782 & 0.343 & 2.676 & 0.102 \\
SBOC & 0.484 & 0.367 & 1.923 & 0.365 & 3.593 & 0.058 \\
WBOC & 0.464 & 0.383 & 1.851 & 0.349 & 1.839 & 0.175 \\
\hline
\end{tabular}

H-FABP, heart type fatty acid binding protein; BOCs, Baicheng oil chickens; Ho, observed heterozygosity; He, expected heterozygosity; Ne, effective number of allele; PIC, polymorphic information content; BBOC, black Baicheng oil chicken; SBOC, silky Baicheng oil chicken; WBOC, white Baicheng oil chicken.

$\mathrm{Ho}, \mathrm{He}, \mathrm{Ne}$, and $x^{2}$ were analyzed by POPGENE software (ver.1.31) and PIC was analyzed by PowerMaker software (ver.3.25).

\section{mRNA expression of the $H$-FABP gene}

The changes in the mRNA expression of the $H-F A B P$ gene with time in the different tissues are shown in Figure 3 and 4. Significant differences in $H$-FABP mRNA expression were detected between 30 and $120 \mathrm{~d}$ in the breast muscles of BBOC $(p=0.001)$, SBOC $(p=0.007)$, and WBOC $(p<$ $0.001)$ as well as in the leg muscles of BBOC $(p<0.001)$, SBOC $(p<0.001)$, and WBOC $(p<0.001)$. Significant differences were also examined between 60 and $120 \mathrm{~d}$ in the breast muscles of SBOC $(p=0.042)$ and in the leg muscles of BBOC $(p=0.007)$ and WBOC $(p=0.044)$. Significant differences were observed between 30 and $90 \mathrm{~d}$ in the breast muscles of BBOC $(p=0.01)$, SBOC $(p=0.048)$, and WBOC $(p<0.001)$. Moreover, significant differences were detected between 30 and $60 \mathrm{~d}$ in the breast muscles of WBOC $(p<0.001)$ and in the leg muscles of BBOC $(p<$ $0.001)$, SBOC $(p<0.001)$, and WBOC $(p=0.001)$. Finally, a significant difference was found between 60 and $90 \mathrm{~d}$ in the

Table 3. Relationship between $H-F A B P$ gene polymorphism and IMF of breast muscle

\begin{tabular}{lcll}
\hline Breed & AA & \multicolumn{1}{c}{ AB } & BB \\
\hline BBOC & $8.781 \pm 0.575^{\mathrm{a}}$ & $6.839 \pm 0.377^{\mathrm{b}}$ & $7.892 \pm 0.315^{\mathrm{ab}}$ \\
SBOC & $6.893 \pm 0.554$ & $5.840 \pm 0.590$ & $6.032 \pm 0.769$ \\
WBOC & $7.401 \pm 0.498$ & $6.038 \pm 0.539$ & $7.149 \pm 0.818$ \\
\hline
\end{tabular}

H-FABP, heart type fatty acid binding protein; IMF, intramuscular fat; BBOC, black Baicheng oil chicken; SBOC, silky Baicheng oil chicken; WBOC, white Baicheng oil chicken.

The correlation between $H-F A B P$ gene polymorphism and IMF content was performed by SAS 9.0 using the SAS software PROC GLM procedures.

${ }_{a, b}$ Means within a row with no common superscript are different $(p<0.05)$.

Table 1. H-FABP genotypic frequency and gene frequency of BOCs

\begin{tabular}{|c|c|c|c|c|c|}
\hline \multirow{2}{*}{ Breed } & \multicolumn{3}{|c|}{ Genotypic frequency (\%) } & \multicolumn{2}{|c|}{ Gene frequency $(\%)$} \\
\hline & AA & $\mathrm{AB}$ & $\mathrm{BB}$ & $\mathrm{A}$ & B \\
\hline BBOC & $0.15(9 / 60)$ & $0.35(21 / 60)$ & $0.50(30 / 60)$ & $0.325(39 / 120)$ & $0.675(81 / 120)$ \\
\hline SBOC & $0.417(25 / 60)$ & $0.366(22 / 60)$ & $0.217(13 / 60)$ & $0.600(72 / 120)$ & $0.400(48 / 120)$ \\
\hline WBOC & $0.450(27 / 60)$ & $0.383(23 / 60)$ & $0.167(10 / 60)$ & $0.642(77 / 120)$ & $0.358(43 / 120)$ \\
\hline
\end{tabular}

H-FABP, heart type fatty acid binding protein; BOCs, Baicheng oil chickens; BBOC, black Baicheng oil chicken; SBOC, silky Baicheng oil chicken; WBOC, white Baicheng oil chicken.

$\mathrm{AA}, \mathrm{AB}$, and $\mathrm{BB}$ were genotypes frequency; A and B were alleles. They were analyzed by POPGENE software (ver.1.31) according to 60 chickens with with a 1:1 sex ratio of each group. 
Table 4. Relationship between $H-F A B P$ gene polymorphism and IMF of leg muscle

\begin{tabular}{lccc}
\hline Breed & AA & AB & BB \\
\hline BBOC & $13.199 \pm 1.060$ & $11.451 \pm 0.649$ & $12.004 \pm 0.580$ \\
SBOC & $9.369 \pm 0.995$ & $8.408 \pm 1.061$ & $9.285 \pm 1.380$ \\
WBOC & $11.958 \pm 0.636^{\mathrm{a}}$ & $9.241 \pm 0.689^{\mathrm{b}}$ & $10.940 \pm 1.05^{\mathrm{ab}}$
\end{tabular}

H-FABP, heart type fatty acid binding protein; IMF, intramuscular fat; BBOC, black Baicheng oil chicken; SBOC, silky Baicheng oil chicken; WBOC, white Baicheng oil chicken.

The correlation between $H-F A B P$ gene polymorphism and IMF content was performed by SAS 9.0 using the SAS software PROC GLM procedures.

${ }^{a, b}$ Means within a row with no common superscript are different $(\mathrm{p}<0.05)$.

leg muscles of BBOC $(\mathrm{p}<0.001)$.

\section{Association between intramuscular fat content and $\mathrm{H}$ - FABP mRNA expression}

The correlation coefficient between IMF and H-FABP mRNA is shown in Table 1. The two parameters were negatively correlated in every muscle of the different types of BOCs. A significant correlation was detected in the leg muscles of WBOC $(p=0.035)$.

\section{DISCUSSION}

The H-FABP is a vital candidate gene for meat quality and promotes fat transportation, utilization, and storage (Zhang et al., 2013). The H-FABP is often found in heart and skeletal muscle tissues, where high fatty acid oxidation occurs; it participates in the delivery of fatty acids to the mitochondria, where $\beta$-oxidation occurs (Heuckeroth et al.,

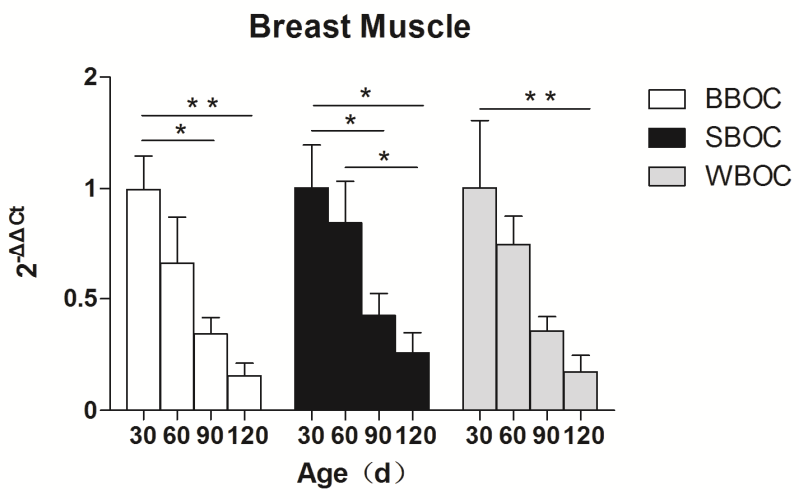

Figure 3. H-FABP mRNA expression weigh in breast muscles of BBOC, SBOC, and WBOC at $30 \mathrm{~d}, 60 \mathrm{~d}, 90 \mathrm{~d}$, and $120 \mathrm{~d}$. Samples of breast muscles of BBOC, SBOC, and WBOC were harvested at $30 \mathrm{~d}, 60 \mathrm{~d}, 90 \mathrm{~d}$, and $120 \mathrm{~d}$. The expression of mRNA for $H-F A B P$ gene was analyzed using quantitative real-time polymerase chain reaction. Data are presented as the mean \pm standard error of the mean for each tissue ( $n=60$ per group). * $\mathrm{p}<0.05 ; * * \mathrm{p}<0.01 ; * * * \mathrm{p}<0.001$. H-FABP, heart-type fatty acidbinding protein; BBOC, black Baicheng oil chicken; SBOC, silky Baicheng oil chicken; WBOC, white Baicheng oil chicken.

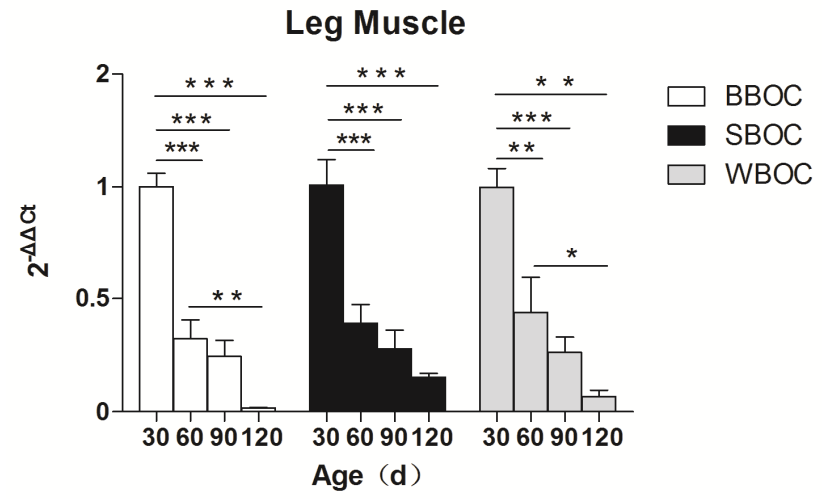

Figure 4. H-FABP mRNA expression weigh in leg muscles of BBOC, SBOC, and WBOC at $30 \mathrm{~d}, 60 \mathrm{~d}, 90 \mathrm{~d}$, and $120 \mathrm{~d}$. Samples of leg muscles of BBOC, SBOC, and WBOC were harvested at $30 \mathrm{~d}, 60 \mathrm{~d}, 90 \mathrm{~d}$, and $120 \mathrm{~d}$. The expression of mRNA for $H-F A B P$ gene was analyzed using quantitative real-time polymerase chain reaction. Data are presented as the mean \pm standard error of the mean for each tissue ( $n=60$ per group). * $\mathrm{p}<0.05 ; * * \mathrm{p}<0.01 ; * * * \mathrm{p}<0.001$. H-FABP, heart-type fatty acidbinding protein; BBOC, black Baicheng oil chicken; SBOC, silky Baicheng oil chicken; WBOC, white Baicheng oil chicken.

1987). Restriction fragment length polymorphism of $\mathrm{H}$ FABP affects IMF content and thus has been used as a marker for selecting increased IMF and growth in swine (Gerbens et al., 1999; Gerbens et al., 2001). Saez et al. (2009) found $A-F A B P$ gene expression and protein were significantly related with IMF content in ducks. It was reported that the BB genotype at A-FABP had significantly higher IMF content in leg muscles and breast muscles than that in $\mathrm{AA}$ and $\mathrm{AB}$ genotype in Beijing-You chickens (Ye et al., 2009). In this study we focused on H-FABP, because it has been confirmed that H-FABP is most important among genes which affect fat content and fatty asid metabolism of chickens (Li et al., 2010).

The increasing of IMF content plays an economic important part in chicken breeding (Ye et al., 2009). However, IMF is seldom used as a selection objective in traditional chicken breeding, because it can't be measured in live chickens (Gardan et al., 2007; Ye et al., 2009). The marker-assisted selection provides more advantages than traditional breeding methods for this special parameter (Ye et al., 2009; Tu et al., 2010). So one aim of the current study

Table 5. Correlations between $H-F A B P$ abundance and IMF content in breast muscle and leg muscle of BOCs

\begin{tabular}{lccc}
\hline & BBOC & SBOC & WBOC \\
\hline Breast muscle & -0.219 & -0.041 & -0.074 \\
Leg muscle & -0.212 & -0.128 & $-0.668^{*}$ \\
\hline
\end{tabular}

H-FABP, heart type fatty acid binding protein; IMF, intramuscular fat; BOCs, Baicheng oil chickens; BBOC, black Baicheng oil chicken; SBOC, silky Baicheng oil chicken; WBOC, white Baicheng oil chicken.

The correlation analysis between mRNA expression $\left(2^{-\Delta C t}\right)$ and IMF content was assessed by Pearson's correlation coefficient of SPSS 17.0 at slaughter time, ${ }^{*} \mathrm{p}<0.05$. 
was to investigate whether mutational cites of $H$-FABP gene second extron could be used to select IMF content of BOC, thus providing basic data for chicken breeding.

The BBOC has been selected for eggs and meat for a period of time and is most popular at locality, SBOC has been selected for treatment of gynecological diseases, and WBOC is main living at the high altitudes because of their chill-proof. The highest IMF content of breast muscles and leg muscles were found in BOC. These findings are consistent with the popularity of the three chickens in the market.

The PIC was at the range of $0.25<\mathrm{PIC}<0.5$ in BOCs, which indicated that these three groups were moderate polymorphism. Several SNPs of H-FABP in chickens have been detected and the genotype of H-FABP has been proved to affect the content of IMF in several chicken breeds (Wang et al., 2007; Ye et al., 2009). In the current study, the IMF content of AA genotype in breast muscle of BBOC and in leg muscle of WBOC were siginificantly higher than those in $\mathrm{AB}$ genotype. These results indicated that the G939A site could be taken as marker for higher IMF content selecting for breast muscle of $\mathrm{BBOC}$ and leg muscle of WBOC in breeding program. The H-FABP has been isolated from kinds of tissues such as cardiac muscle, skeletal muscle, lung, aorta, brain, adrenal gland, renal cortex, mammary gland, ovary, placenta and adipose tissue (Bai et al., 2013). There are several reports on H-FABP gene mRNA expression (Tyra et al., 2011). These data indicate that H-FABP has a wider biological function than expected (Pang et al., 2006). In these reports, it is common that it was mainly expressed in cardiac muscle, chest muscle and leg muscle (Zschiesche et al., 1995; Gerbens et al., 1999; Tu et al., 2010), results of mRNA expression in present study further proved their conclusions.

In the present study, the expression profiles of the $\mathrm{H}$ $F A B P$ gene were determined in the breast and leg muscles of BOCs, and the correlation between mRNA expression and IMF content was analyzed. This analysis was based on the relevance of this gene with lipid metabolism and its effect on fatness parameters (Li et al., 2007) and IMF content (Tyra et al., 2011). Although H-FABP expression in muscles correlates with the absorption and transport of fatty acids in cells, it is not associated with adipogenesis (Tyra et al., 2011).

The assay of real- time PCR had been used to measure the transcription level of interesting genes because of its sensitivity and specificity ( $\mathrm{Tu}$ et al., 2010; Chen et al., 2011). It was reported that $H-F A B P$ mRNA expression of an oxidative muscle was higher than that of a glycolytic muscle in cattle (Brandstetter et al., 2002). The mRNA expression level of $H-F A B P$ is higher in subcutaneous adipocytes than in intramuscular adipocytes in different tissues of growing pigs at both 80-day-old and 210-day-old; what's more, transcript levels isolated from subcutaneous adipocytes at 80-day-old was higher than that isolated from intramuscular adipocytes at 210-day-old (Gardan et al., 2007). Ontogenesis stages (fetus, 7-day-old, and 5-monthold) significantly affect the mRNA expression of $H$-FABP in porcine ( $\mathrm{Li}$ et al., 2007). $H$-FABP mRNA level peaks in the subcutaneous fat near the wither, then in the visceral fat of perienal, visceral fat of omental, and subcutaneous fat near the base of the tail of Lanzhou fat-tailed sheep (Bai et al., 2013). In chickens, H-FABP influences fat content and fatty acid metabolism (Li et al., 2010). The H-FABP mRNA level in chicken varies depending on breed, tissues in which the mRNA expression level is examined, and age. Many researchers investigated the effects of tissue type or animal age on mRNA expression. However, there is no one report about BOC. In the present study, we focused on the effects of both tissue type and animal age on the mRNA expression of $H$-FABP. An analysis in chest and thigh muscles has shown that the mRNA expression level of $H-F A B P$ peaks at $30 \mathrm{~d}$ and then decreases with age. Similarly, Tu et al. (2010) found that the $H-F A B P$ mRNA expression at $56 \mathrm{~d}$ is higher than that at $120 \mathrm{~d}$. Rump et al. (1996) proved that H-FABP protein level is high in the skeletal muscle of mice during the first days after birth and can remain high up to $30 \mathrm{~d}$. This observation can be attributed to the differentiation of skeletal muscle cells, that is, the transformation of myoblasts into myotubes (Tyra et al., 2011), and they indicate that the $H-F A B P$ transcript abundance in semimembranosus and longissimus dorsi muscles of all the researched breeds (Duroc, Pietrain, Puławska, Polish Large White, and Polish Landrace) of all onto genesis stages (60-, 90-, 12, 50, 180- and 210-d-old) do not exhibit any siginificant changes. Li et al. (2007) observed the mRNA expression levels of $H-F A B P$ at the fetus, 7-dayold, and 5-month-old stages of pig ontogenesis and found that age significantly affects $H-F A B P$ mRNA expression level, so they considered that the $H-F A B P$ gene played an important part in adipose tissue development and function in the swine.

The H-FABP influences IMF content (Li et al., 2007). The present results showed that the mRNA expression of the $H-F A B P$ gene negatively affects the IMF contents in the chest and leg muscles of BOCs. Similar results were observed in Rugao and Luyuan chickens (Tu et al., 2010). $\mathrm{Li}$ et al. (2010) also found that low leg IMF content indicates high $H$-FABP mRNA expression. This phenomenon demonstrates that the relatively high expression of $H-F A B P$ mRNA increases fat metabolism and promotes lipolysis to produce more energy and satisfy the requirements of growth, reproduction, and other physiological processes (Li et al., 2010). Guglielmo et al. (2002) noticed the similar occurrence in migratory birds, they clarified that $H$-FABP mRNA level of chest uscles 
were highest in the process of migration (10\%) and improving $H-F A B P$ expression might be carried out by endurance fling training.

\section{CONCLUSION}

The G939A site could be taken as genetic marker for higher IMF content selecting for breast muscle of BBOC and leg muscle of WBOC. The IMF content increases and $H$-FABP gene mRNA abundance decreases with age. The mRNA expression of the $H-F A B P$ gene negatively correlates with IMF content in both breast and leg muscles of BOCs.

\section{CONFLICT OF INTEREST}

We certify that there is no conflict of interest with any financial organization regarding the material discussed in the manuscript.

\section{ACKNOWLEDGMENTS}

This study was supported by the National Natural Science Foundation of China (Project No. 31160521), Tarim University Principal Fund (Project No. TDZKGG201504) and the project of Key Laboratory of Tarim Animal Husbandry Science and Technology, Xinjiang Production \& Construction Group (Project No. HS201302).

\section{REFERENCES}

Amanguli, Y., M. Renaguli, Y. Fang, K. Amannisha, and H. Rebila. 2014. Comparative analysis analysis of the lipid composition of Baicheng fatty chicken and local chicken. Xinjiang Agricultural Sciences 51:552-557.

Bai, J. L., H. W. Xu, R. X. Zang, H. J. He, Y. Cai, X. Cao, F. J. Peng, J. Han, J. P. Wu, and J. T. Yang. 2013. Cloning of the heart fatty acid-binding protein $(H-F A B P)$ gene and its tissuespecific expression profile in the Lanzhou fat-tailed sheep, Ovis aries. Small Rumin. Res. 112:114-122.

Brandstetter, A. M., H. Sauerwein, J. H. Veerkamp, Y. Geay, and J. F. Hocquette. 2002. Effects of muscle type, castration, age and growth rate on $H-F A B P$ expression in bovine skeletal muscle. Livest. Prod. Sci. 75:199-208.

Chen, R., Z. P. Yang, D. J. Ji, Y. J. Mao, Y. Chen, Y. L. Li, H. T. Wu, X. L. Wang, and L. L. Chang. 2011. Polymorphisms of the IL8 gene correlate with milking traits, SCS and mRNA level in Chinese Holstein. Mol. Biol. Rep. 38:4083-4088.

Chmurzynska, A. 2006. The multigene family of fatty acid-binding proteins (FABPs): Function, structure and polymorphism. J. Appl. Genet. 47:39-48.

Cho, E. S., D. H. Park, B-W. Kim, W. Y. Jung, E. J. Kwon, and C. W. Kim. 2009. Association of GHRH, H-FABP and MYOG polymorphisms with economic traits in pigs. Asian Australas. J. Anim. Sci. 22:307-312.

Gardan, D., I. Louveau, and F. Gondret. 2007. Adipocyte- and heart-type fatty acid binding proteins are both expressed in subcutaneous and intramuscular porcine (Sus scrofa) adipocytes. Comp. Biochem. Physiol. Part B: Biochem. Mol. Biol. 148:14-19.

Gemenggul, M., Y. Wang, L. Liu, H. Wang, X. Feng, L. Cheng, and A. Wumaierjiang. 2013. Measurement of baicheng-oil chicken germplasm characteristics. China Poultry 35(22):5760 .

Gerbens, F., A. J. Van Erp, F. L. Harders, F. J. Verburg, T. H. Meuwissen, J. H. Veerkamp, and M. F. Te Pas. 1999. Effect of genetic variants of the heart fatty acid-binding protein gene on intramuscular fat and performance traits in pigs. J. Anim. Sci. 77:846-852.

Gerbens, F., F. J. Verburg, H. T. Van Moerkerk, B. Engel, W. Buist, J. H. Veerkamp, and M. F. Te Pas. 2001. Associations of heart and adipocyte fatty acid-binding protein gene expression with intramuscular fat content in pigs. J. Anim. Sci. 79:347-354.

Guglielmo, C. G., N. H. Haunerland, P. W. Hochachka, and T. D. Williams. 2002. Seasonal dynamics of flight muscle fatty acid binding protein and catabolic enzymes in a migratory shorebird. Am. J. Physiol. Regul. Integr. Comp. Physiol. 282:R1405-R1413.

Heuckeroth, R. O., E. H. Birkenmeier, M. S. Levin, and J. I. Gordon. 1987. Analysis of the tissue-specific expression, developmental regulation, and linkage relationships of a rodent gene encoding heart fatty acid binding protein. J. Biol. Chem. 262:9709-9717.

Hocquette, J., F. Gondret, E. Baéza, F. Médale, C. Jurie, and D. Pethick. 2010. Intramuscular fat content in meat-producing animals: development, genetic and nutritional control, and identification of putative markers. Animal 4:303-319.

Huang, Z. G., X. Li, Z. S. Liu, Y. Qiao, S. R. Liu, H. X. Ren, X. Zhuang, G. Q. Liu, and X. B. Li. 2006. The developmental changes and effect on IMF content of H-FABP and PPARy mRNA expression in sheep muscle. Acta Genetica Sinica 33:507-514.

Li, B., H. N. Zerby, and K. Lee. 2007. Heart fatty acid binding protein is upregulated during porcine adipocyte development. J. Anim. Sci. 85:1651-1659.

Li, H., G. Wu, J. Zhang, and N. Yang. 2010. Identification of the heart-type fatty acid-binding protein as a major gene for chicken fatty acid metabolism by Bayesian network analysis. Poult. Sci. 89:1825-1833.

Li, W. J., H. B. Li, J. L. Chen, G. P. Zhao, M. Q. Zheng, and J. Wen. 2008. Gene expression of heart- and adipocyte-fatty acid-binding protein and correlation with intramuscular fat in Chinese chickens. Anim. Biotechnol. 19:190-194.

Li, X. Q., Y. H. Zhu, H. F. Zhang, Y. Yue, Z. X. Cai, Q. P. Lu, L. Zhang, G. W. Xiao, F. J. Zhang, D. Zhou, C. Y. Jin, and J. F. Wang. 2012. Risks associated with high-dose Lactobacillus rhamnosus in an Escherichia coli model of piglet diarrhoea: intestinal microbiota and immune imbalances. PloS one 7(7):e40666

Ma, X., X. Ren, P. Han, S. Hu, J. Wang, and J. Yin. 2010. SiRNA against Fabp5 induces 3T3-L1 cells apoptosis during adipocytic induction. Mol. Biol. Rep. 37:4003-4011.

Pang, W. J., L. Bai, and G. S. Yang. 2006. Relationship among $H$ FABP gene polymorphism, intramuscular fat content, and adipocyte lipid droplet content in main pig breeds with 
different genotypes in Western China. Acta Genetica Sinica 33: 515-524.

Rump, R., C. Buhlmann, T. Borchers, and F. Spener. 1996. Differentiation-dependent expression of heart type fatty acidbinding protein in $\mathrm{C} 2 \mathrm{C} 12$ muscle cells. Eur. J. Cell biol. 69: 135-142.

Saez, G., S. Davail, G. Gentès, J. F. Hocquette, T. Jourdan, P. Degrace, and E. Baéza. 2009. Gene expression and protein content in relation to intramuscular fat content in Muscovy and Pekin ducks. Poult. Sci. 88:2382-2391.

Tu, Y. J., Y. J. Su, K. H. Wang, X. Y. Zhang, H. Tong, and Y. S. Gao. 2010. Gene expression of heart and adipocyte fatty acidbinding protein in chickens by FQ-RT-PCR. Asian Australas. J. Anim. Sci. 23:987-992.

Tyra, M., K. Ropka-Molik, R. Eckert, K. Piórkowska, and M. Oczkowicz. 2011. H-FABP and LEPR gene expression profile in skeletal muscles and liver during ontogenesis in various breeds of pigs. Domest. Anim. Endocrinol. 40:147-154.
Wang, Y., M. Chang, H. Zhong, and W. Li. 2013. Cloning and sequence analysis of baicheng-oil chicken IFN- $\gamma$. J. Tarim Univ. 3:59-63.

Wang, Y., D. M. Shu, L. Li, H. Qu, C. Yang, and Q. Zhu. 2007. Identification of single nucleotide polymorphism of $H$-FABP gene and its association with fatness traits in chickens. Asian Australas. J. Anim. Sci. 20:1812-1819.

Ye, M., J. L. Chen, G. P. Zhao, M. Q. Zheng, and J. Wen. 2009. Associations of $A-F A B P$ and H-FABP markers with the content of intramuscular fat in Beijing-You chicken. Anim. Biotechnol. 21:14-24.

Zhang, Y. J., Y. Q. Liu, J. Song, S. Y. Cheng, and L. X. Dong. 2013. Effects of dietary energy level on the transcription of the $\mathrm{H}$ $F A B P$ gene in different tissues of sheep. Small Rumin. Res. 115:29-33.

Zschiesche, W., A. H. Kleine, E. Spitzer, J. H. Veerkamp, and J. F. C. Glatz. 1995. Histochemical localization of heart-type fattyacid binding protein in human and murine tissues. Histochem. Cell Biol. 103:147-156. 